\title{
MYASTHENIC PATIENTS' IgG CAUSES REDISTRIBUTION OF ACETYLCHOLINE RECEPTORS: FREEZE-FRACTURE STUDIES ${ }^{1}$
}

\author{
DAVID W. PUMPLIN* AND DANIEL B. DRACHMAN $\ddagger^{2}$ \\ * Department of Anatomy, University of Maryland Medical School, Baltimore, Maryland 21202 and $\ddagger$ Department of \\ Neurology, The Johns Hopkins University School of Medicine, Baltimore, Maryland 21205.
}

Received August 10, 1982; Accepted September 30, 1982

\begin{abstract}
Immunoglobulin from patients with myasthenia gravis (MG) accelerates the degradation of acetylcholine receptors (AChRs) of skeletal muscle by a mechanism dependent on receptor crosslinking. However, the intermediate steps between cross-linking and endocytosis and degradation are not known. We have used freeze-fracture electron microscopy to study the effects of myasthenic immunoglobulin on the distribution of AChRs in the surface membranes of cultured rat skeletal muscle. Large, angular intramembrane particles were identified as AChRs. These particles were present in three configurations: distributed individually; in "hot spots"; and in clusters of two to 60 particles. Large depressions (>100 nm in diameter) were thought to be endocytotic pits; they occurred preferentially in hot spots, and approximately half of the depressions were closely associated with clusters of AChRs.

In control myotubes, hot spots contained a high density of AChR particles that were evenly, rather than randomly, distributed. Exposure to myasthenic patients' IgG induced clustering of the particles within such hot spots. In non-hot spot regions, control myotubes had mainly individually distributed AChRs, while clusters were seen only rarely. The addition of myasthenic IgG caused a rapid increase, followed by a gradual decrease, in the incidence of individual clusters as well as an increase in cluster size.

This redistribution of particles was dependent on cross-linking by the myasthenic anti-AChR antibodies. Monovalent Fab fragments of myasthenic IgG had no effect on the distribution of AChR particles. However, addition of a second "piggyback" antibody to cross-link Fab-AChR complexes caused a redistribution of AChR particles like that due to the original myasthenic $\operatorname{IgG}$.

These findings indicate that cross-linking of AChRs by divalent antibody causes clustering of AChR particles, which may play an important role in their accelerated endocytosis and degradation.
\end{abstract}

Myasthenia gravis (MG) is a neuromuscular disorder of man characterized by weakness and fatigability of muscles. The basic defect is a decrease of available acetylcholine receptors (AChRs) at neuromuscular junctions (Fambrough et al., 1973), due to an autoimmune attack (reviewed in Drachman, 1981). A humoral immune mechanism has been implicated in the pathogenesis of MG by the finding in most myasthenic patients of circulating antibodies against AChR (Almon et al., 1974; Bender et al., 1975; Lindstrom et al., 1976) capable of reproducing

\footnotetext{
We thank R. N. Adams for his skilled technical assistance, T. S. Reese for the use of EM and darkroom facilities, and C. F. BarlowSalemi for help in preparation of the manuscript. D. W. P. is supported by National Institute of Health Grant NS-15513. D. B. D. is supported by National Institutes of Health Grants 5 PO1 NS10920 and 5 RO1 H.D04817.

${ }^{2}$ To whom correspondence should be addressed.
}

the typical features of the disease on passive transfer to mice (Toyka et al., 1977).

One potentially important action of the antibody has been suggested by the observation that it increases the rate of degradation of AChRs both in cultured skeletal muscle (Appel et al., 1977; Bevan et al., 1977; Kao and Drachman, 1977) and at intact neuromuscular junctions (Stanley and Drachman, 1978). This effect requires crosslinking of AChRs by the antibodies (Drachman et al., 1978). However, the intermediate steps between crosslinking and endocytosis and degradation are not known. Studies at the light microscopic level (Lennon, 1978; Prives et al., 1979) suggest that anti-AChR antibodies cause a redistribution of presumptive AChRs of skeletal muscle in culture. However, the fluorescence and autoradiographic methods used in those studies do not distinguish adequately between AChRs on the surface and AChRs which have been internalized, and only permit 
the visualization of relatively large groupings of receptors. To avoid these problems and to observe the redistribution at a higher level of resolution, we used a freezefracture technique, which visualizes AChRs as distinctive intramembrane particles in cultured myotubes (Peng and Nakajima, 1978; Yee et, al., 1978; Cohen and Pumplin, 1979). Our findings show that cross-linking of AChRs by divalent antibodies from myasthenic patients causes redistribution of $\mathrm{AChR}$ particles in a consistent fashion. These changes may relate to the ability of myasthenic patients' IgG to induce accelerated endocytosis and degradation of AChRs.

\section{Materials and Methods}

Cultures. Cultures of rat myotubes were prepared from 19-day-old rat fetuses by conventional methods (Yaffe, 1973; Kao and Drachman, 1977) and were grown on gelatin-coated plastic or glass coverslips. The cultures were incubated at $37^{\circ} \mathrm{C}$ under an atmosphere of $10 \%$ carbon dioxide in Eagle's minimum essential medium with Earle's salts, supplemented with $10 \%$ horse serum, 100 units $/ \mathrm{ml}$ of streptomycin, and $2.5 \mu \mathrm{g} / \mathrm{ml}$ of amphotericin $\mathrm{B}$. The number of fibroblasts was minimized by selective plating of the dissociated cells in plastic flasks and by treating 2-day-old cultures with $10^{-5} \mathrm{M}$ cytosine arabinoside for 48 to $72 \mathrm{hr}$.

Preparation of IgG and fragments. Five patients with the diagnosis of MG (established by history, physical examination, decremental responses on repetitive nerve stimulation, and improvement of muscle strength with anticholinesterase agents) gave informed consent for the wilhdrawal of $200 \mathrm{ml}$ of blood. These palients were selected because their respective sera had high titers of antibodies against rat extrajunctional $\mathrm{AChR}$ and produced accelerated degradation of AChRs in muscle cultures (Kao and Drachman, 1977). It should be noted that the effects of these sera were not exceptional; immunoglobulin from more than $90 \%$ of patients with MG produced significant acceleration of AChR degradation in tissue cultures (Drachman et al., 1982). Pooled blood from 10 to 30 normal persons or unselected patients with diseases other than MG was used for control experiments. The serum was removed from clotted blood and stored at $-70^{\circ} \mathrm{C}$ until further processing.

Immunoglobulin $\mathrm{G}$ (IgG) was prepared by a method of ion exchange chromatography that results in a preparation free of other immunoglobulins and complement (Williams and Chase, 1976). Approximately $25 \mathrm{ml}$ of serum from each of five individual myasthenic patients and the control pool were dialyzed against $0.02 \mathrm{M}$ phosphate buffer, $\mathrm{pH} 7.2$, and chromatographed on $2 \times 20 \mathrm{~cm}$ columns of Whatman DE 52; the same buffer was used for elution. IgG was concentrated by vacuum dialysis to 6 to $7 \mathrm{mg} / \mathrm{ml}$.

Fab fragments were prepared from IgG by a papaindigestion method (Putnam et al., 1962) modified to minimize damage to the antibody (Drachman et al., 1978). To remove $\mathrm{Fc}$ fragments and any remaining IgG from the digest, affinity chromatography was carried out using a 5-ml column of staphylococcal protein A covalently linked to Sepharose 4B. Protein A produced by certain strains of Staphylococcus aureus is known to absorb Fc and IgG (with the exception of subclass $\operatorname{IgG}_{3}$ ) specifically
(Kronvall and Williams, 1969). The concentration of Fab in the eluate was adjusted by ultrafiltration (Amicon) so that the AChR binding titer would be equal to that of the same patient's IgG preparation.

$\left.\mathrm{F}(\mathrm{ab})_{2}\right)_{2}$ was prepared by pepsin digestion of $\operatorname{IgG}$ from myasthenic patients as previously described (Drachman et al., 1978). $\mathrm{F}\left(\mathrm{ab}^{\prime}\right)_{2}$ was separated by chromatography on a Sephadex G-100 column, eluted with 0.05 m Tris buffer, $\mathrm{pH} 8.0$ with $0.15 \mathrm{~m}$ sodium chloride. The concentration of $\mathrm{F}\left(\mathrm{ab}^{\prime}\right)_{2}$ was adjusted by vacuum dialysis so that the AChR binding titer would correspond to that of the same patient's IgG.

Treatment of cultures with immunoglobulin preparations. After 6 days in culture, the myotubes were incubated with immunoglobulin preparations ( $10 \%$ by volume in culture medium) for 0.5 to $8 \mathrm{hr}$ at $37^{\circ} \mathrm{C}$. In view of the patients' high serum titers, this represented a large excess of anti-AChR antibodies over AChRs in the cultures. In a group of experiments using Fab fragments, a second incubation with goat antihuman IgG at $10 \%$ concentration was carried out for $4 \mathrm{hr}$.

Freeze-fracture methods. After antibody incubation, the cultures were fixed with $5 \%$ glutaraldehyde in $0.12 \mathrm{M}$ sodium cacodylate buffer, $\mathrm{pH} 7.2$, for $1 \mathrm{hr}$ at $4^{\circ} \mathrm{C}$ and rinsed with the same buffer. The coverslips with adherent fixed myotubes were gradually equilibrated to $33 \%$ glycerol in water. Areas with myotubes were selected by phase microscopy, and 4-mm diameter circles were cut out of the coverslips. Freeze-fracture was performed by the method of Pauli et al. (1977). A drop of 30\% polyvinyl alcohol (Gelvatol 20-30, Monsanto, New York, NY) in $33 \%$ glycerol $-\mathrm{H}_{2} \mathrm{O}$ was placed on a specimen carrier made for tissue cultures (Balzers AG, Nashua, NH). The circle from the coverslip was inverted onto the drop, and the resulting sandwich was frozen in liquid Freon-22 (Matheson, Rutherford, NJ) maintained near its freezing point, then stored in liquid $\mathrm{N}_{2}$. Fracture and replication were carried out at $-119^{\circ} \mathrm{C}$ under a vacuum of $10^{-6}$ torr in a Balzers $301 \mathrm{M}$ apparatus equipped with a complementary replica device. Specimen carriers were placed in a small dish to which water or $33 \%$ glycerol was slowly added to dissolve the polyvinyl alcohol layer and float off the replica. Replicas were cleaned in sodium hypochlorite solution and cut into several pieces which were picked up on Formvar-coated slotted grids for electron microscopy.

Replicas of myotubes as free as possible from artifacts due to fixation and freezing were selected for study: particles were sharply defined, and complementary pits were present; membranes contained an apparently evenly dispersed population of "background" particles, without clumping or particle-free areas. The fracture plane tended to pass through that portion of the myotube adjacent to the gelatin substrate, resulting in a preponderance of cytoplasmic leaflets (P-faces) in replicas obtained from the specimen carrier side; cross-fractured cytoplasm was rarely seen.

Analysis of AChR configurations. Large angular intramembrane particles, identified as AChRs by several criteria, were found in three configurations (described under "Results"). The following measurements were made on two configurations, hot spots and clusters.

1. Hot spots. The distribution of particles in hot spots 
of myotubes treated with control or myasthenic IgG was tested for deviations from a random distribution. To do this, micrographs of portions of a hot spot were divided into 100 to 200 equal areas by a transparent grid overlay. The number of particles within each area was counted, and a histogram was prepared of the number of areas having successive numbers of particles. If the original distribution were random, such a histogram would have a Poisson distribution (Cohen and Pumplin, 1979; Land et al., 1977). The observed distribution was compared by a $\chi^{2}$ test (Dixon and Massey, 1957) with a Poisson distribution having the same mean and total number of areas.

2. Clusters. (a) The number of particles per cluster was determined by hand counting of 379 clusters in control myotubes and 621 clusters in myasthenic IgGtreated myotubes. (b) For studies on the time course of IgG effects on individual clusters, the incidence of individual clusters per unit membrane area was determined by sampling areas $\left(69\right.$ or $\left.74 \mu \mathrm{m}^{2}\right)$ chosen at random from myotubes in a replica. From 10 to 29 areas were sampled at each time point. 'To avoid bias, areas were chosen at a low magnification where individual particles could not be distinguished. Clusters were counted in prints at an overall magnification of 55,000. Areas found to contain hot spots were rejected from the count.

\section{Results}

Appearance of freeze-fractured normal rat myotubes. The membrane feature most intensively investigated was a class of particles approximately $10 \mathrm{~nm}$ in diameter which, together with their platinum shadows, were distinctly angular in shape. These particles are thought to be the freeze-fracture representations of $\mathrm{AChRs}$ on the basis of morphological and pharmacological evidence. Particles with this appearance predominate at the peaks of post-synaptic folds of neuromuscular junctions of amphibians and mammals (Heuser and Reese, 1977), and they have also been seen in cultured myotubes of Xenopus (Peng and Nakajima, 1978; Cohen and Pumplin, 1979; Yee et al., 1978). The presence of $10-\mathrm{nm}$ particles is associated with high sensitivity to iontophorctically applied $\mathrm{ACh}$ (Yee et al., 1978), and their distribution in the membranes matches the distribution of binding of $\alpha$-bungarotoxin, a ligand which is specific for AChR (Cohen and Pumplin, 1979).

The 10-nm angular particles were found singly, in "hot spots," and in clusters.

"Hot spots" were readily identificd large collections of AChRs extending several tens of microns along the myotubes, and often occupying the entire width of the exposed membrane $(10$ to $20 \mu \mathrm{m})$. A portion of a hot spot in a control myotube is shown in Figure 1. Such hot spots on the lower myotube surface adjacent to the substrate are invariably associated with sites of myotube attachment (Bloch and Geiger, 1980). The concentration of particles within the hot spot was high $\left(750\right.$ to $\left.1000 / \mu^{2}\right)$, and the borders were well defined by a sharp fall-off of the concentration of large particles. Some portions of hot spots were composed of several bands or patches with similar sharp borders. In control myotubes, the interparticle spacing within a hot spot was relatively even (Fig. 1). The spacing differed significantly $(p<0.025)$ from a random distribution (see "Materials and Methods"). This particle arrangement in hot spots of rat muscle differs from that in chick (Cohen and Pumplin, 1979) or Xenopus (Peng and Nakajima, 1978).

Clusters (Fig. 2) contained 2 to 60 parlicles which were closely packed into roughly circular areas at a concentration of about 1400 particles/ $\mu \mathrm{m}^{2}$. Particles within a cluster appeared to be closely similar in size and shape, although they were not completely uniform. Clusters of the larger sizes would be just visible with fluorescence microscopy as tiny points (Pumplin, unpublished). Smaller "background" particles did not form clusters.

Large depressions. Large (100-nm diameter) rounded depressions (Fig. 2) were observed and counted. Depressions of similar size and appearance have been seen in freeze-fracture replicas of cultured fibroblasts and have been equated with coated pits (Rohlich and Allison, 1976; Orci et al., 1978). They were preferentially found in hot spots and areas that had large numbers of clusters of AChRs. Within hot spots, the density of depressions was $0.118 / \mu \mathrm{m}^{2}$, whereas the density of depressions in non-hot spot membrane was only $0.011 / \mu \mathrm{m}^{2}$. These depressions had a close relationship with $\mathrm{AChR}$ particles. Of 273 depressions examined, $52 \%$ actually contained AChR particles, and an additional $25 \%$ were contiguous to $\mathrm{AChR}$ particles (Fig. 2).

Small depressions. Small depressions (50- to $70-\mathrm{nm}$ diameter) appeared either singly or in groups (Figs. 1 to 3). These small depressions are thought to be caveolae and/or openings to the developing T-tubule system (Cohen and Pumplin, 1979; Ezerman and Ishikawa, 1967). Small depressions had no obvious relationship to clusters, nor did they preferentially occur in hot spots. The small depressions never contained AChR particles. Of 229 small depressions examined, $37 \%$ ) had 1 to 32 particles at their edges, while the remaining $63 \%$ were more than $50 \mathrm{~nm}$ from the nearest $\mathrm{AChR}$ particle.

Effects of myasthenic IgG on freeze-fracture appearance of myotubes: hot spots. After incubation with IgG from myasthenic patients, the arrangement of $\mathrm{AChR}$ particles within the hot spots was strikingly different from that in control rat myotubes. Instead of the even spacing normally found, the particles were redistributed into tight clusters, separated by open spaces (Figs. 1 and $3)$. The particle density within the clusters was about $1400 / \mu \mathrm{m}^{2}$, comparable to that of individual clusters outside hot spots, and more closely packed than particles in normal hot spots.

The distribution of particles in hot spots of control and myasthenic IgG-treated myotubes was analyzed statistically for deviation from a random distribution (Fig. 4) as described under "Materials and Methods." Hot spots in control myotubes had a more even spacing of particles than would be predicted by a random distribution $(p<0.025)$. By contrast, the AChR particles in hot spots on myasthenic IgG-treated myotubes were less evenly distributed (i.e., clustered) than predicted by chance $(p<0.01)$. Thus the distribution of particles was clearly different in the control and myasthenic IgG-treated hot spots.

Clumping of particles in hot spots increased progressively with longer durations of exposure to myasthenic IgG (Fig. 3) (up to $4 \mathrm{hr}$ ), but there was little if any change beyond $4 \mathrm{hr}$ of exposure. This redistribution of AChR 


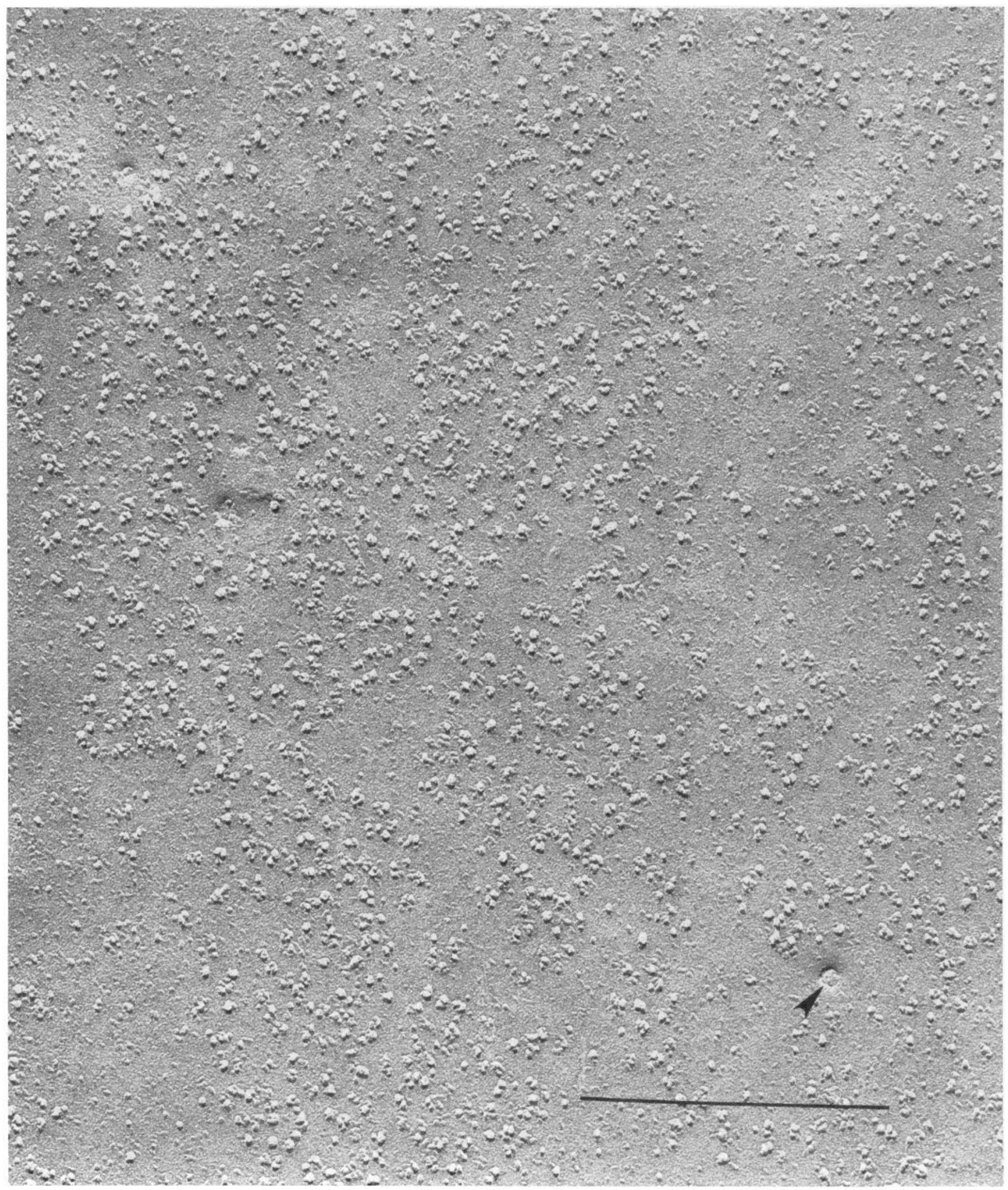

Figure 1. Portion of a hot spot on a normal rat myotube. All micrographs are P-faces of the myotube surfaces adjacent to the substrate. Large angular intramembrane particles (AChRs) are evenly distributed. Compare with the clustered distributions of AChRs in antibody-treated hot spots (Fig. 3). A few caveolae are present (arrow). Bar, $0.5 \mu \mathrm{m}$. 

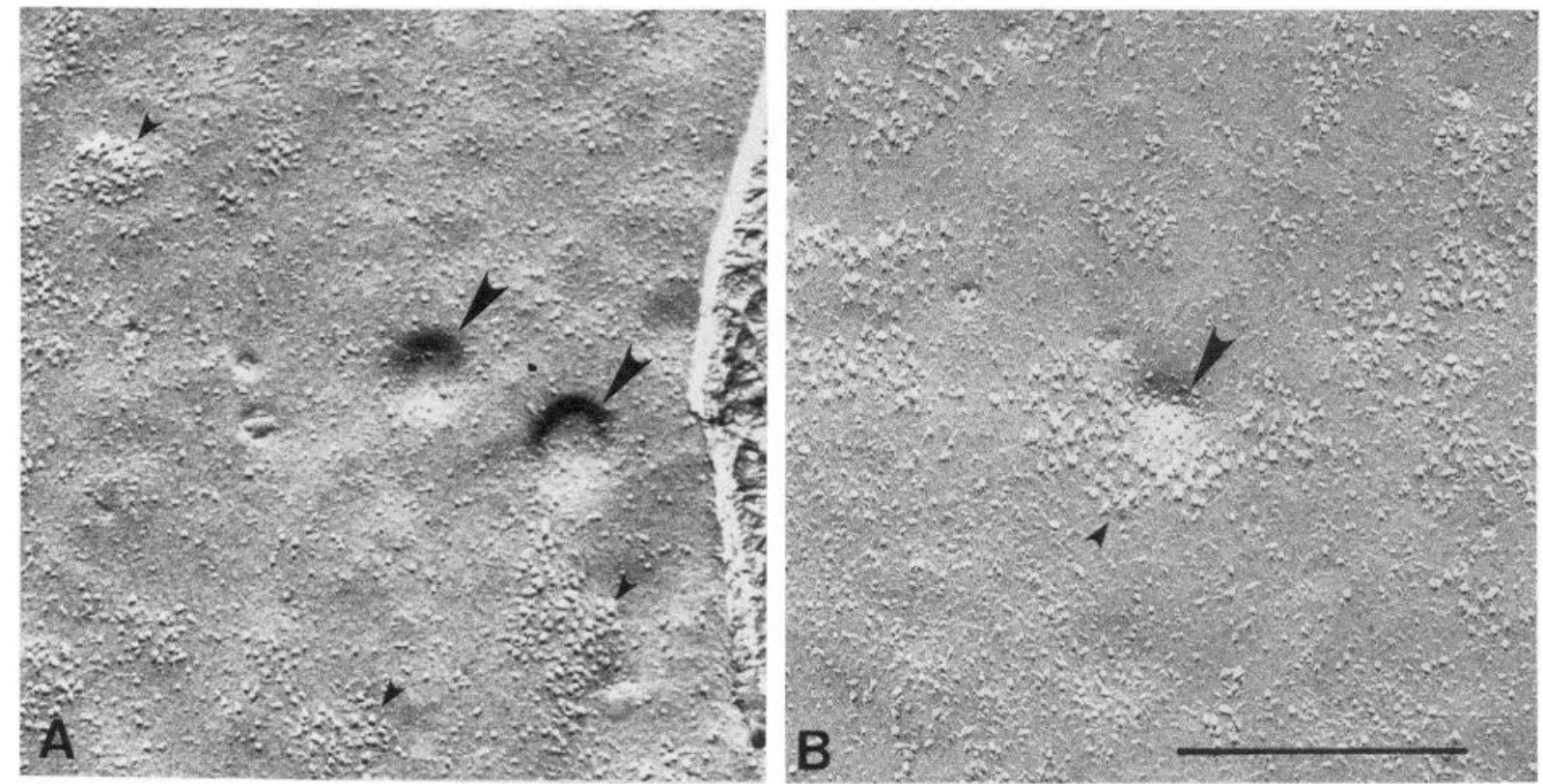

Figure 2. Relationships between clusters (small arrows) of AChR particles and large (> $100 \mathrm{~nm}$ ) depressions (large arrows). In $A$ the depressions are not associated with nearby clusters, whereas in $B$ a portion of a cluster extends into the depression. $B a r$, $0.5 \mu \mathrm{m}$.

particles in hot spots was consistently induced by myasthenic IgG from five different patients.

Effects of antibody fragments on cultured myotubes. Monovalent Fab fragments prepared from myasthenic IgG produced no change in the distribution of AChR particles in hot spots (Table I). However, the addition of a second "piggyback" antibody against human IgG, to cross-link the Fab-AChR complexes, resulted in a redistribution of intramembrane particles that was qualitatively identical to that seen after treatment with myasthenic IgG. Divalent $\mathrm{F}\left(\mathrm{ab}^{\prime}\right)_{2}$ fragments of myasthenic IgG also redistributed AChRs (Table I).

These findings support the concept that the rearrangement of AChRs is dependent on cross-linking by divalent antibodies.

Clusters. Treatment of myotubes with myasthenic patients' IgG produced a marked, rapid increase in clustering of AChR particles followed by a gradual disappearance of the clusters (Fig. 5). In untreated myotubes or those treated with control IgG, individual clusters were relatively rare $\left(0.07 \pm 0.02 \mu \mathrm{m}^{2}\right.$; mean $\left.\pm \mathrm{SEM} ; \mathrm{N}=25\right)$. Thirty minutes after addition of myasthenic IgG, the incidence of clusters rose 8 -fold to $0.56 \pm 0.07$; with more prolonged exposure to IgG, the incidence of individual clusters declined (Fig. 5). A first-order (exponential) curve, fitted to the data from $30 \mathrm{~min}$ to $10 \mathrm{hr}$ by least squares, indicated a half-life of $10.0 \mathrm{hr}$ for clusters exposed to myasthenic IgG.

In addition to the effect of myasthenic patients' IgG on the incidence of clusters, the antibody caused a small but significant increase in cluster size. The histogram of sizes of clusters containing four or more particles was well fitted by an exponential curve (Fig. 6). Myotubes treated with myasthenic IgGs from four different patients had a significantly higher $(p<0.01)$ incidence of larger clusters than did control myotubes (Fig. 6). In some cultures, the AChR clusters appeared to be grouped in large aggregates. These aggregates were approximately 10 to $30 \mu \mathrm{m}$ long and contained numerous clusters of tightly packed AChRs, with intervening distances of $>$ $0.3 \mu \mathrm{m}$ between clusters. We were unable to determine the true incidence of these aggregates because of the limited surface area that can be surveyed by freezefracture electron microscopy.

\section{Discussion}

The major finding in this study is that IgG from myasthenic patients caused a consistent pattern of rearrangement of $\mathrm{AChR}$ particles in cultured mammalian skeletal muscle. The AChRs became grouped together in tight clusters of up to 60 particles each. In the IgGtreated cultures, clustering occurred both within hot spots and throughout the remainder of the muscle surface membrane.

Cluster formation required the presence of divalent antibodies directed against AChRs. Myasthenic IgG, or its divalent $\mathrm{F}\left(\mathrm{ab}^{\prime}\right)_{2}$ fragments, induced $\mathrm{AChR}$ clustering; monovalent Fab fragments did not. However, when Fab fragments were first bound to the muscle AChRs and were then cross-linked by a "piggyback" antibody directed against the Fabs, clustering occurred. This strongly suggests that cross-linking of AChRs by the divalent antibody is responsible for their rearrangement into clusters. Furthermore, the distance between AChR particles within a cluster is consistent with the span of an IgG molecule. In this study, the concentration of Pface particles in clusters was about $1400 / \mu \mathrm{m}^{2}$. An additional $0.6 \times 1400=850 / \mu \mathrm{m}^{2}$ particles occur in the corresponding E face (Cohen and Pumplin, 1979; D. W. Pumplin and R. J. Bloch, unpublished observation), giving a total concentration of 2250 particles $/ \mu \mathrm{m}^{2}$. At this density, the distance between centers of the particles would be $210 \AA$. Since the particles have a diameter of $80 \AA$ (exclusive of the platinum coat), the average interparticle 

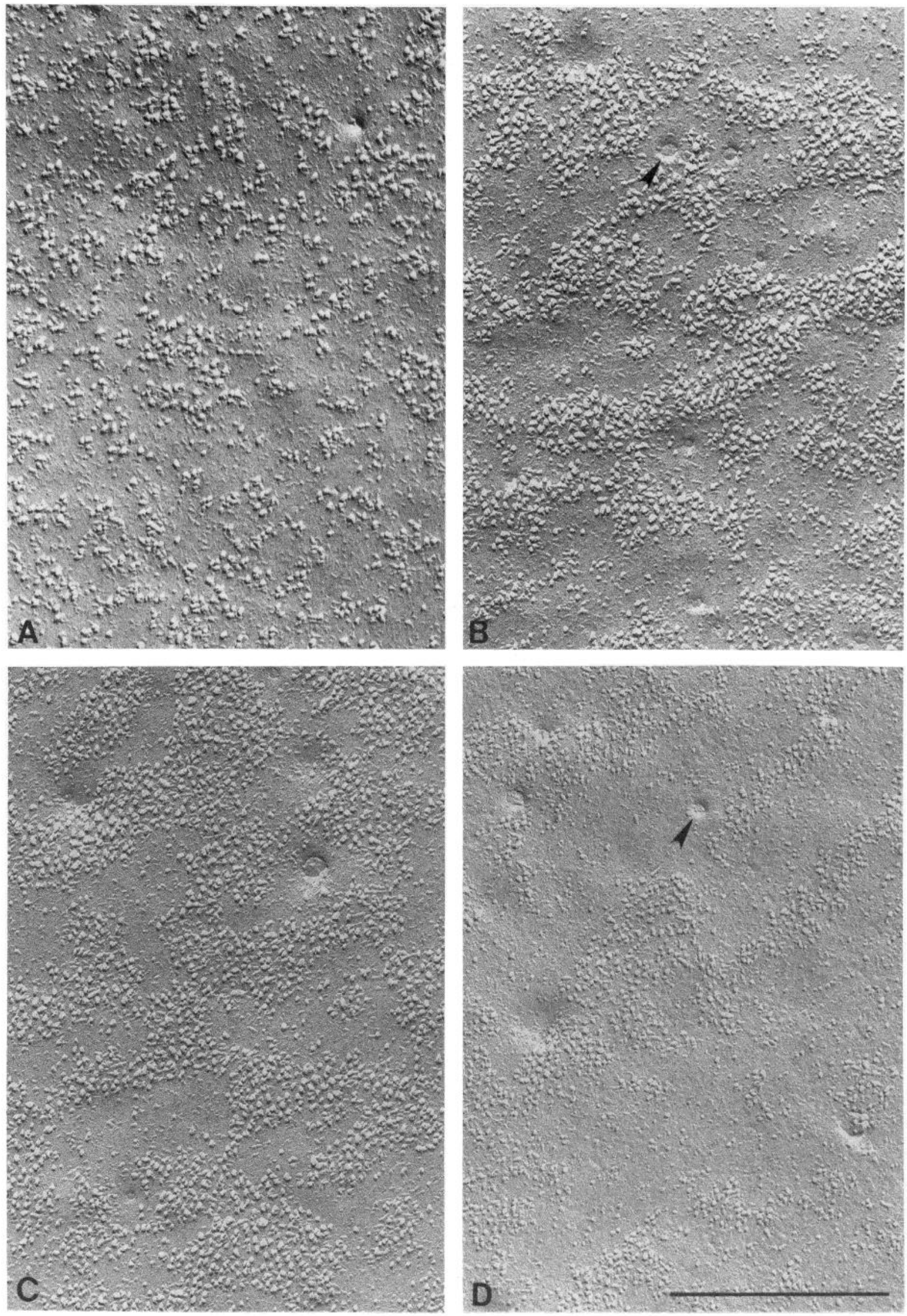

Figure 3. Portions of hot spots in myotubes treated with myasthenic IgG (compare with Fig. 1). Illustrated are myotubes incubated $1 \mathrm{hr}(A) ; 2 \mathrm{hr}(B)$; and $8 \mathrm{hr}(C)$ at $37^{\circ} \mathrm{C}$ with myasthenic IgG. The AChR particles are relatively evenly spaced in control myotubes (Fig. 1) but become increasingly clustered by exposure to the antibody. Cross-linking of previously bound Fab fragments by goat antirabbit IgG also caused redistribution of AChR particles $(D)$. Small "background" particles are present in the spaces between clusters. Several caveolae are seen (arrows). Bar for all micrographs, $0.5 \mu \mathrm{m}$. 


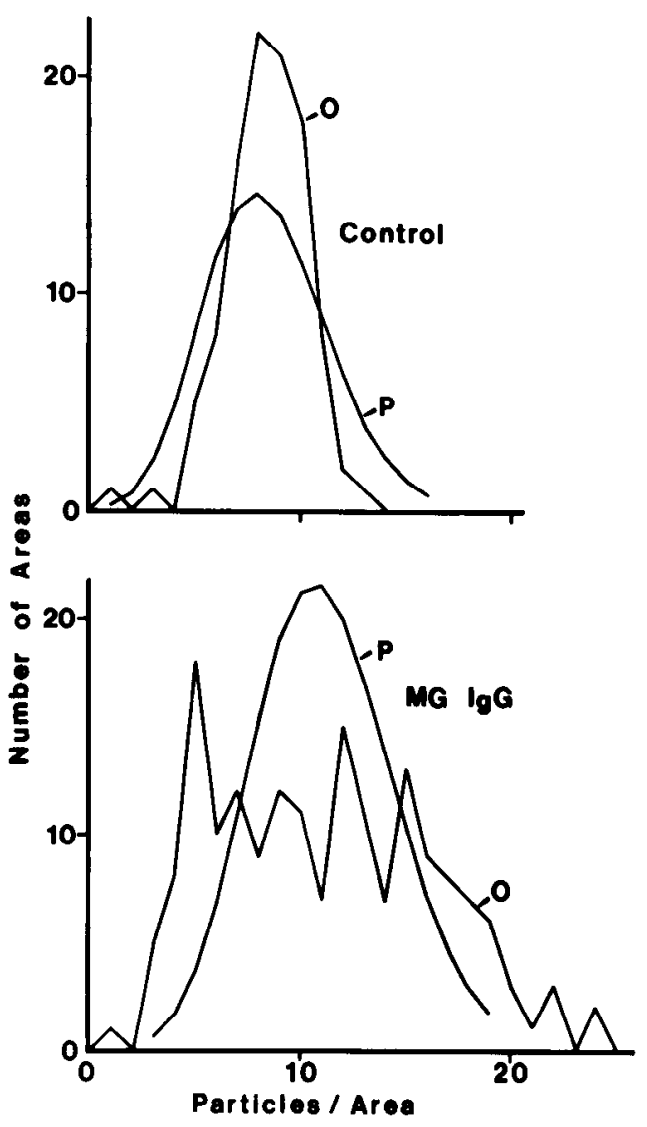

Figure 4. Histograms showing distribution of particles within hot spots. The distribution of particles was obtained by dividing micrographs into a large number of equal-sized areas and counting the number of particles in each area. A random distribution of particles would produce a histogram having a Poisson distribution (curve indicated by $P$ in each case). In control myotubes, the observed distribution (curve $O$ in the upper graph) was narrower than the Poisson distribution with the same mean and total number of areas, indicating that the particles are more evenly spaced than expected for a random distribution. In all five micrographs tested, the deviation from Poisson was significant ( $p<0.025 ; \chi^{2}$ test) (Dixon and Massey, 1957). In myotubes treated with myasthenic IgG (lower panel), the histogram was wider than the corresponding Poisson distribution, indicating a larger than expected number of areas with high and low concentrations of particles, respectively, resulting from $A C h R$ clustering. The deviation was significant ( $p<0.001 ; \chi^{2}$ test). All distributions are defined only at integral values of particles/ area; these points have been connected for clarity.

TABLE I

Effect of myasthenic IgG on redistribution of AChRs in hot spots

\begin{tabular}{|c|c|c|c|c|}
\hline Cultures Treated & Cultures & $\begin{array}{c}\text { Fibers Ex- } \\
\text { amined }\end{array}$ & $\begin{array}{l}\text { Numbers of } \\
\text { Hot Spots }\end{array}$ & $\begin{array}{l}\text { Distribution of } \\
\text { AChRs in Hot } \\
\text { Spots }\end{array}$ \\
\hline & & & & Clustered Even \\
\hline
\end{tabular}

Medium alone or nonmyasthenic $\operatorname{IgG}$

$M G \operatorname{IgG}$

MG F $\left(\mathrm{ab}^{\prime}\right)_{2}$

MG Fab

$\mathrm{MG} \mathrm{Fab}+$ goat antihuman IgG

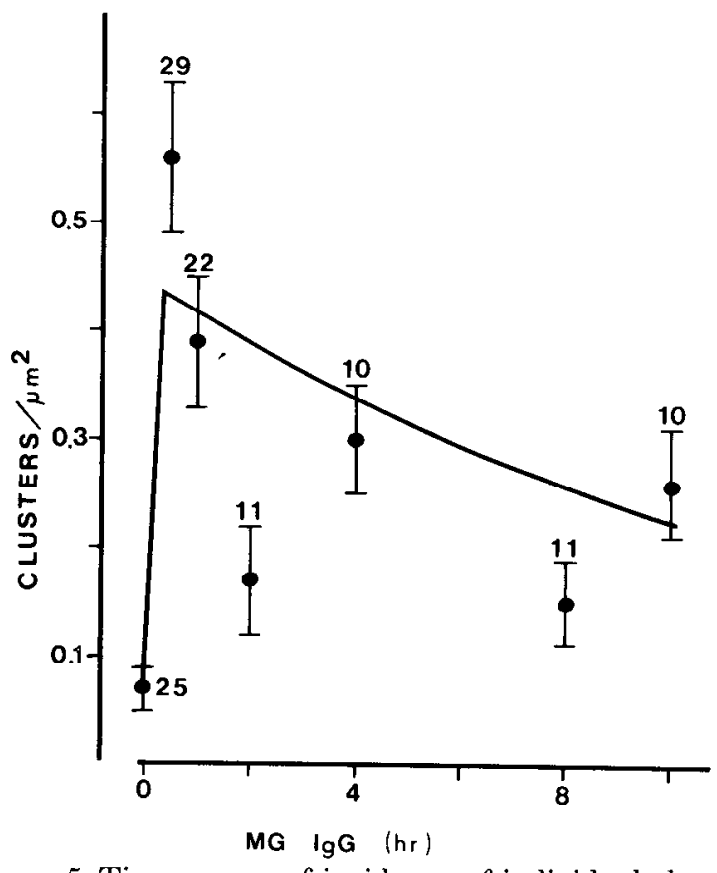

Figure 5. Time course of incidence of individual clusters in myotubes exposed to myasthenic IgG. The incidence of clusters is low in unexposed cultures, rises rapidly in the first $30 \mathrm{~min}$ of exposure to IgG, then gradually falls. Each time point is the mean \pm SEM of the number of clusters found in micrographs taken of randomly chosen 69 or $74-\mu \mathrm{m}^{2}$ area of myotube membrane. The number of areas counted is indicated. The solid line is a first order (exponential) least-squares fit to the data from $30 \mathrm{~min}$ to $10 \mathrm{hr}$. The slope of the (nearly identical) straight line fit was significantly different from zero $(\rho<0.01)$, indicating a significant decrease in cluster incidence over this period. The exponential fit yields a half-life for clusters of $10 \mathrm{hr}$.

distance would be approximately $130 \AA$, which is not far from the maximum span of an IgG molecule of $120 \AA$ (Valentine and Green, 1967).

The rearrangement of particles in hot spots and nonhot spot regions entails certain differences that are probably due to the structural relationship of the particles to the muscle cells. It has previously been suggested that AChRs within hot spots are anchored to an underlying cytoskeleton (Axelrod et al., 1976; Bloch, 1979; Bloch and Geiger, 1980), whereas elsewhere AChRs have far greater mobility (Axelrod et al., 1976; Anderson and Cohen, 1977). Our observations show a nonrandom, evenly spaced arrangement of AChR particles in hot spots of normal rat myotubes. The interparticle distance is too large to allow for direct interactions between neighboring receptors, but the ordered pattern could be maintained by a subjacent cytoskeleton. Treatment with myasthenic patients' IgG produced relatively slow clustering of $\mathrm{AChR}$ particles in hot spots. Cluster formation increased gradually, reaching a maximum by about $4 \mathrm{hr}$. In nonhot spot regions of muscle membrane, the process appears much more rapid, reaching a peak within $1 / 2 \mathrm{hr}$ followed by a subsequent slow decline. This suggests that a high affinity interaction between the antibodies and AChRs (Bray and Drachman, 1982) within hot spots disrupts the AChR-cytoskeletal scaffold, gradually resulting in clustering. In non-hot spot regions, the mobile AChRs could be redistributed rapidly to form clusters well within the observed time of $1 / 2 \mathrm{hr}$ or less. In several 


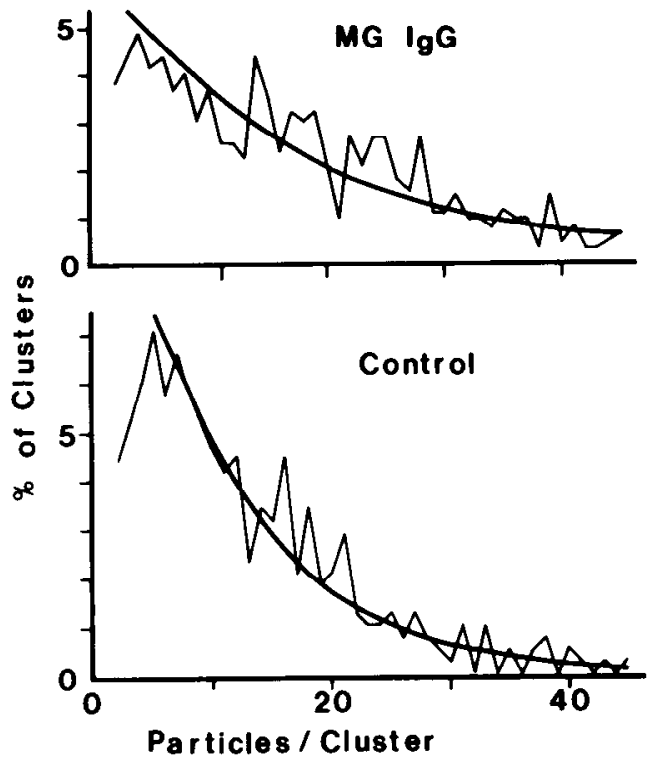

Figure 6. Histograms of sizes of individual clusters in control and antibody-treated myotubes. In both cases, the number of clusters containing more than four particles was fitted by an exponential curve, which may be explained on theoretical grounds (Cohen and Pumplin, 1979). Treatment with myasthenic IgG $\left(4 \mathrm{hr}, 37^{\circ} \mathrm{C}\right.$; data from four patients) increased the relative abundance of large clusters, shifting the curve to the right. The two histograms are significantly different $(p<0.01$; Kolmogorov-Smirnoff test on the cumulative form of the distributions).

cultures treated with myasthenic patients' IgG, we saw large aggregates of clustered AChR particles. These aggregates could represent the "patches" reported in previous studies using light microscopy with autoradiographic (Prives et al., 1979) or fluorescence (Lennon, 1978) techniques, although these techniques cannot distinguish surface from internalized receptors. Such aggregates were seen only occasionally in our material, possibly due to the limited amount of surface area that can be examined by freeze-fracture electron microscopy.

Antibody-mediated rearrangement and accelerated degradation of AChRs. It is now well established that antibodies directed against AChRs play a key role in the pathogenesis of MG. These antibodies are thought to produce a reduction of available AChRs by at least three different mechanisms: (1) accelerated degradation of AChRs (Appel et al., 1977; Bevan et al., 1977; Kao and Drachman, 1977; Stanley and Drachman, 1978; Reiness et al., 1978); (2) blockade of the active sites of AChRs (Almon et al., 1974; Drachman et al., 1982; Fulpius et al., 1982;); and (3) complement-mediated damage to AChRs (Toyka et al., 1977; Engel et al., 1979). There is considcrablc evidence that the rearrangement of AChRs described here may represent an early step in the process of accelerated degradation of AChRs. Degradation of receptors in normal muscle cells is thought to begin with internalization via endocytotic pits. The internalized receptors are degraded by lysosomal enzymes, and the products of degradation are released from the muscle cell. Endocytosis, rather than lysosomal degradation of $\mathrm{AChRs}$, seems to be the rate-limiting step; the rate of loss of surface AChRs is not altered by inhibition of lysosomal enzymes (Drachman et al., 1980; Libby et al., 1980). The rearrangement of AChR particles observed in this study could trigger the accelerated endocytosis previously observed. Cross-linking of the receptors by divalent antibodies is required for both rearrangement and rapid degradation of $\mathrm{AChRs}$. Furthermore, the rapid loss of surface receptors in muscle cultures treated with myasthenic patients' antibodies is paralleled by the loss of clustered AChRs reported here. Our observations suggest that the $100-\mathrm{nm}$ depressions may serve as the vehicles for endocytosis of the receptors. In the present study, these pits were closely associated with clusters of AChRs, and they often had AChR particles extending into their openings. A number of other surface membrane proteins have been shown to be internalized by similar processes of ligand binding, clustering, and internalization of the clustered proteins via clathrin-coated pits (Goldstein et al., 1979; Pastan and Willingham, 1981). For example, receptors for insulin, low density lipoprotein, and epidermal growth factor have been shown to undergo similar processes of clustering and endocytosis (Schlessinger et al., 1978; Haigler et al., 1979; Zidovetsky et al., 1981). In those cases, ligand-induced endocytosis may play a physiological role in transporting the ligand to an intracellular site of action (Schlessinger et al., 1978). By contrast, the effect of myasthenic antibodies on AChRs does not mimic the interaction of the normal ligand with its receptor, but rather represents a pathological process by which the receptor is rapidly degraded.

In conclusion, our findings show that divalent antibodies from myasthenic patients induce redistribution of AChRs to form small clusters. The initial increase and subsequent loss of AChR clusters occurs pari passu with their accelerated degradation. Endocylotic pits may serve as the vehicles for internalization of the clustered AChRs prior to their degradation. We suggest that the clustered AChRs are recognized by the muscle cell membrane, perhaps because of altered arrangement or mobility, and selected for preferential degradation. In any case, cluster formation seems to be an intermediate step between the cross-linking of AChRs by antibodies and their subsequent accelerated degradation.

\section{References}

Almon, R. R., C. G. Andrew, and S. H. Appel (1974) Serum globulin in myasthenia gravis: Inhibition of $\alpha$-bungarotoxin binding to acetylcholine receptors. Science 186: 55-57.

Anderson, M. J., and M. W. Cohen (1977) Nerve-induced and spontaneous redistribution of acetylcholine receptors on cultured muscle cells. J. Physiol. 268: 757-773.

Appel, S. H., R. Anwyl, M. W. McAdanns, and S. Elias (1977) Accelerated degradation of acetylcholine receptor from cultured rat myotubes with myasthenia gravis sera and globulins. Proc. Natl. Acad. Sci. U. S. A. 74: 2130-2134.

Axelrod, D., P. Ravdin, D. E. Koppel, J. Schlessinger, W. W. Webb, E. L. Elson, and T. R. Podleski (1976) Latcral motion of fluorescent-labeled acetylcholine receptors in membranes of developing muscle fibers. Proc. Natl. Acad. Sci. U. S. A. 73: 4594-4598.

Bender, A. N., S. P. Ringel, W. K. Engel, M. P. Daniels, and Z. Vogel (1975) Myasthenia gravis: A serum factor blocking acetylcholine receptor of the human neuromuscular junction. Lancet 1: 607-609.

Bevan, S., K. W. Kullberg, and S. F'. Heinemann (1977) Human myasthenic sera reduce acetylcholine sensitivity of human muscle cells in tissue culture. Nature 267: 263-265.

Bloch, R. J. (1979) Dispersal and reformation of acetylcholine receptor clusters of cultured rat myotubes treated with inhib- 
itors of energy metabolism. J. Cell Biol. 82: 626-643.

Bloch, R. J., and B. Geiger (1980) The localization of acetylcholine receptor clusters in areas of cell-substrate contact in cultures of rat myotubes. Cell 21: 25-35.

Bray, J. J., and D. B. Drachman (1982) Binding affinities of anti-acetylcholine receptor autoantibodies in myasthenia gravis. J. Immunol. 128: 105-110.

Cohen, S. A., and D. W. Pumplin (1979) Clusters of intramembrane particles associated with binding sites for $\alpha$-bungarotoxin in cultured chick myotubes. J. Cell Biol. 82: 494-516.

Dixon, W. J., and F. J. Massey (1957) Introduction to Stalistical Analysis. ed. 2, McGraw-Hill, New York.

Drachman, D. B. (1981) The biology of myasthenia gravis. Annu. Rev. Neurosci. 4: 195-225.

Drachman, D. B., C. W. Angus, R. N. Adams, J. D. Michelson, and G. J. Hoffman (1978) Myasthenic antibodies cross-link acetylcholine receptors to accelerate degradation. N. Engl. J. Med. 298: 1116-1122.

Drachman, D. B., A. Pestronk, E. F. Stanley, and R. N. Adams (1980) Mechanisms of acetylcholine receptor loss in myasthenia gravis. In Diseases of the Motor Unit, D. L. Schotland, ed., pp. 215-231., John Wiley and Sons, New York.

Drachman, D. B., R. N. Adams, L. F. Josifek, and S. G. Self (1982) Functional activities of anti-AChR autoantibodies and clinical severity of myasthenia gravis. N. Engl. J. Med. 307: $769-775$

Engel, A. G., K. Sahashi, E. H. Lambert, and F. M. Howard (1979) The ultrastructural localization of the acetylcholine receptor, immunoglobulin $G$, and the third and ninth complement components at the motor endplate and their implications for the pathogenesis of myasthenia gravis. In Current Topics in Nerve and Muscle Research, A. J. Aguayo and G. Karpati, eds., International Congress Series Vol. 455; pp. $111-$ 122, Excerpta Medica, Amsterdam.

Ezerman, E. B., and H. Ishikawa (1967) Differentiation of the sarcoplasmic reticulum and $\mathrm{T}$ system in developing chick skeletal muscle in vitro. J. Cell Biol. 35: 405-420.

Fambrough, D. M., D. B. Drachman, and S. Satyamurti (1973) Neuromuscular junction in myasthenia gravis: Decreased acetylcholine receptor. Science 182: 293-295.

Fulpius, B. W., A. K. Lefvert, S. Cuénoud, and A. Mourey (1982) Properties and serum levels of specific populations of anti-acetylcholine receptor antibodies in myasthenia gravis. Ann. N. Y. Acad. Sci. 377: 307-315.

Goldstein, J., R. Anderson, and M. Brown (1979) Coated pits, coated vesicles and receptor mediated endocytosis. Nature (Lond.) 279: 679-684.

Haigler, A. T., J. A. McKanna, and S. Cohen (1979) Direct visualization of the binding and internalization of a ferritin conjugate of epidermal growth factor in human carcinoma cells A-431. J. Cell Biol. 81: 382-395.

Heuser, J. E., and T. S. Reese (1977) Structure of the synapse. In Handbook of Physiology - The Nervous System I E. Kandel, ed., pp. 261-294. American Physiology Society, Washington, D.C.

Kao, I., and D. B. Drachman (1977) Myasthenic immunoglobulin accelerates acetylcholine receptor degradation. Science 196: 527-529.

Kronvall, G., and R. C. Williams, Jr. (1969) Difference in staphylococcal protein A activity among IgG subgroups. J. Immunol. 103: 828-833.

Land, B. R., T. R. Podleski, E. E. Salpeter, and M. M. Salpeter (1977) Acetylcholine receptor distribution on myotubes in culture correlated to acetylcholine sensitivity. J. Physiol. 269: $155-176$.

Lennon, V. A. (1978) Immunofluorescence analysis of surface acetylcholine receptors on muscle: Modulation by auto-antibodies. In Cholinergic Mechanisms and Psychopharmacology, D. S. Jenden, ed., pp. 77-92, Plenum Press, New York.
Libby, P., S. Bursztajn, and A. J. Goldberg (1980) Degradation of the acetylcholine receptor in cultured muscle cells: Selective inhibitors and the fate of undegraded receptors. Cell 9: 481-491.

Lindstrom, J. M., M. E. Seybold, V. A. Lennon, S. Whittingham, and D. D. Duane (1976) Antibody to acetylcholine receptor in myasthenia gravis: Prevalence, clinical correlates, and diagnostic value. Neurology (Minneap.) 26: 1054-1059.

Orci, L., J-L. Carpentier, A. Perrelet, R. G. W. Anderson, J. L. Goldstein and M. S. Brown (1978) Occurrence of low density lipoprotein receptors within large pits on the surface of human fibroblasts as demonstrated by freeze-etching. Exp. Cell Res. 113: 1-13.

Pastan, I. H., and M. C. Willingham (1981) Receptor-mediated endocytosis of hormones. Annu. Rev. Physiol. 43: 239-250.

Pauli, B. V., R. S. Weinstein, L. W. Soble, and J. Alroy (1977) Freeze-fracture of monolayer cultures. J. Cell Biol. 72: 763769.

Peng, H. B., and Y. Nakajima (1978) Membrane particle aggregates in innervated and non-innervated cultures of Xenopus embryonic muscle cells. Proc. Nall. Acad. Sci. U. S. A. 75: 500-504.

Prives, J., L. Hoffman, R. Tarrab-Hazdai, S. Fuchs, and A. Amsterdam (1979) Ligand induced changes in stability and distribution of acetylcholine receptors on surface membranes of muscle cells. Life Sci. 24: 1713-1718.

Putnam, F. W., M. Tan, L. T. Lynn, C. W. Easley, and S. Migita (1962) The cleavage of rabbit $\alpha$-globulin by papain. J. Biol. Chem. 237: 717-726.

Reiness, C. G., C. B. Weinberg and Z. W. Hall (1978) Antibody to acetylcholine receptor increases degradation of junctional and extrajunctional receptors in adult muscles. Nature 274: 68-70.

Rohlich, P., and A. C. Allison (1976) Oriented pattern of membrane-associated vesicles in fibroblasts. J. Ultrastruc. Res. 57: 94-103.

Schlessinger, J., Y. Schechter, M. C. Willingham, and I. Pastan (1978) Direct visualization of binding, aggregation and internalization of insulin and epidermal growth factor on living fibroblastic cells. Proc. Natl. Acad. Sci. U. S. A. 75: 26592663.

Stanley, E. F., and D. B. Drachman (1978) Effect of myasthenic immunoglobulin on acetylcholine receptors of intact mammalian neuromuscular junctions. Science 200: 1285-1287.

Toyka, K. V., D. B. Drachman, D. E. Griffin, A. Pestronk, J. A. Winkelstein, K. H. Fischbeck, and I. Kao (1977) Myasthenia gravis: Study of humoral immune mechanisms by passive transfer to mice. N. Engl. J. Med. 256: 125-131.

Valentine, R. C., and M. M. Green (1967) Electron microscopy of antibody-hapten complexes. J. Mol. Biol. 27: 615-617.

Williams, C. A., and M. W. Chase, eds. (1967) Methods in Immunology and Immunochemistry, Vol. 1, pp. 321-332, Academic Press, New York.

Willingham, M. C., F. R. Maxfield, and I. H. Pastan (1979) $\alpha-2$ Macroglobulin binding to the plasma membrane of cultured fibroblasts. Diffuse binding followed by clustering in coated regions. J. Cell Biol. 82: 614-625.

Yaffe, D. (1973) Rat skeletal muscle cells. In Tissue Culture: Methods and Applications, P. Kruse, Jr., and M. K. Patterson, eds., pp. 106-113, Academic Press, New York.

Yee, A. G., G. Fischbach, and M. Karnovsky (1978) Clusters of intramembranous particles on cultured myotubes at sites that are highly sensitive to acetylcholine. Proc. Natl. Acad. Sci. U. S. A. 75: 3004-3008.

Zidovetsky, R., Y. Yarden, J. Schlessinger, and T. M. Jovin (1981) Rotational diffusion of epidermal growth factor complexed to cell surface receptors reflects rapid microaggregation and endocytosis of occupied receptors. Proc. Natl. Acad. Sci. U. S. A. 78: 6981-6985. 